\title{
Predicting void ratio for surface paste tailings deposition
}

\author{
E.R. Salfate University of British Columbia, Canada \\ G.W. Wilson University of British Columbia, Canada \\ D. Wijewickreme University of British Columbia, Canada \\ P. Simms Carleton University, Canada
}

\begin{abstract}
Paste tailings have proven to be a reliable technology with advantages in terms of safety and water savings. Although safety is always the priority when designing this type of facilities, effective water usage has turned out to be of special importance for dry regions where the benefits of saving water often justify the use of this technology. Current design requirements have revealed the need to reliably predict the deposited and postdeposited void ratio and density of the paste. These properties are fundamental for determining the stability of paste impoundments, especially under undrained conditions. This paper presents an overview of the modelling framework under which some of the initial properties of paste tailings can be predicted. The approach is based on the application of unsaturated soil mechanics, through which drying and volume change of the paste can be related. The results using this framework seem to correlate well with those from drying tests performed in the laboratory, thus confirming the validity of the modelling approach. Several case scenarios were evaluated using this modelling framework. Variables such as paste layer thickness, drying time of the paste, and climate have been modified to observe their effect over water content and void ratio distribution. The results presented herein demonstrate how void ratio and density of the paste would change under different operational and climatic conditions. The long-term goal of the research is to develop a model that may be used as a planning tool during the design stages of paste tailings storage facilities.
\end{abstract}

\section{Introduction}

The purpose of this paper is to present a framework under which the evolution of void ratio for paste tailings layers during drying can be predicted. This framework has been previously used by Simms et al. (2007) and Fisseha et al. (2010) but without explicitly showing results in terms of void ratio distribution.

After disposal, paste tailings undergo a series of processes that result in an increase of density and strength of the material. Within the processes that affect tailings density, the following are considered the most relevant:

- Self-weight consolidation and settlement after deposition: Paste tailings often undergo some volume change immediately after deposition. This deformation is a result of the loads imposed by the weight of the material and subsequent de-watering due to minor excess pore water pressures.

- Drying and drainage: Depending on the existing climatic conditions and disposal scheme, paste tailings will be subject to drying through evaporation and further de-watering due to downward drainage. During this stage, the tailings shrink as a result of water being extracted from the pores along with the associated increase in matric suction. The stages of self-weight consolidation, drainage and drying generally occur progressively after the tailings are exposed to the environment.

- Consolidation: Consolidation occurs due to the loads imposed by subsequent paste tailings lifts. The rate and amount of consolidation will depend on the void ratio obtained after drying and drainage. Different consolidation curves are obtained for different initial void ratios and therefore, being able to predict the final void ratio after deposition becomes highly relevant.

According to the mechanisms outlined above, we hypothesise that the stress path for a typical paste tailings layer after deposition would look similar to that presented in Figure 1. 


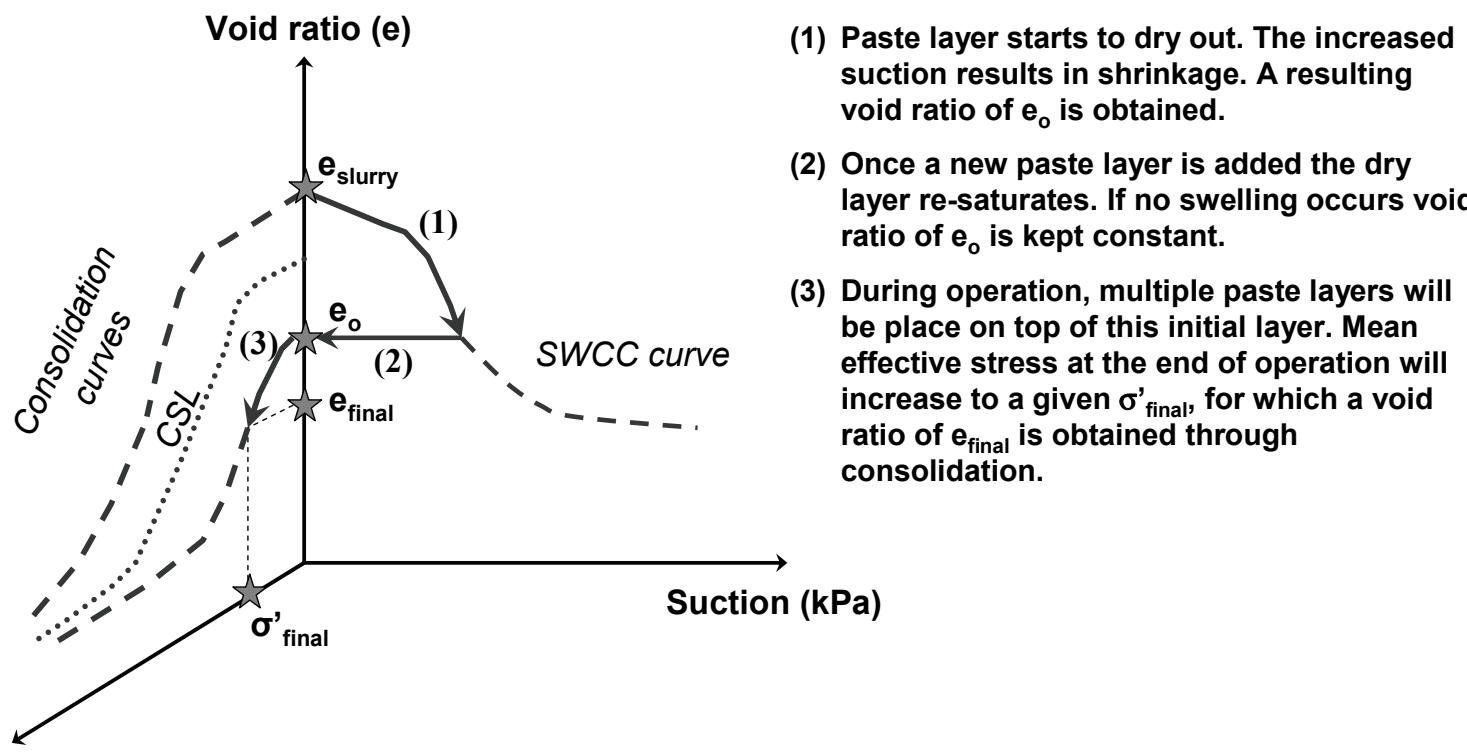

\section{Effective Stress (kPa)}

\section{Figure 1 Idealised stress path for a single paste layer}

The following sections will focus on the prediction of void ratio during the drying, drainage and re-saturation stages that are represented by curves (1) and (2) in Figure 1. The void ratio determined by the framework presented herein may be then used to determine the subsequent amount of consolidation shown as curve (3), as well as other relevant parameters required during design.

\section{Relevance of predicting void ratio during design stages}

Physical stability of paste tailings stacks is a key consideration in design. Several issues should be assessed in order to ensure both short and long-term stability of these impoundments. Among these issues, liquefaction of the paste and the possibility of a flow slide is probably one the greatest concerns during design. Density is considered to be one of the key parameters affecting the response of the material under cyclic loading. In very simple terms, denser materials will tend to have a higher resistance to liquefaction than loose materials at the same confining stress. A problem emerges from the fact that densities are not readily available during design stages and therefore predictive tools are required to estimate this parameter.

In addition to the need to predict void ratio for liquefaction assessment, void ratio evolution may also be useful when trying to determine parameters such as undrained shear strength of the paste with time. If void ratio is properly determined, then the undrained shear strength may be obtained by using a curve relating void ratio or water content to shear vane measurements. As an example of a potential application, the oil sands industry is required under Directive 74 to obtain trafficable conditions on the deposited tailings. The performance criteria are based on requiring the achievement of minimum undrained shear strength of $5 \mathrm{kPa}$ after one year of deposition. The approach presented in this paper will assist in determining the time required to achieve this goal and help determine the most appropriate thin layer deposition scheme.

\section{$3 \quad$ Material properties}

Data generated from paste tailings from the Bulyanhulu gold mine in Tanzania were used for the models presented in this paper. A summary of the properties for the Bulyanhulu tailings is shown in Table 1. 
Table 1 Properties of Bulyanhulu paste tailings

\begin{tabular}{|c|c|c|}
\hline Property & Units & Value \\
\hline Specific gravity & - & 2.98 \\
\hline PL, LL, SL & $\%$ & $20,23,18$ \\
\hline Saturated hydraulic conductivity ${ }^{(1)}$ & $\mathrm{m} / \mathrm{s}$ & $5.0 \times 10^{-7}$ \\
\hline $\begin{array}{l}\text { Pumping gravimetric water content } \\
\text { (calculated) })^{(2)}\end{array}$ & $\%$ & 45.3 \\
\hline $\begin{array}{l}\text { Porosity at pumping water content } \\
\text { (calculated) })^{(2)}\end{array}$ & $\%$ & 57.4 \\
\hline Void ratio at the shrinkage limit & - & 0.79 \\
\hline
\end{tabular}

\subsection{Settling and self-weight consolidation}

Settling and self-weight consolidation, play an important role in the evolution of void ratio. In arid climates and for relatively dewatered tailings deposited in thin layers, the rate of settling is quickly overtaken by evaporation; however, in humid climates settling and self-weight consolidation may be very important to densification of tailings (Simms et al., 2009b). For the Bulyanhulu tailings it was observed that the void ratio could decrease from approximately 1.35 (measured void ratio at slurry conditions) to a void ratio of 1.0 after settling and self-weight consolidation. This effect was observed even when thin layers of $5 \mathrm{~cm}$ were prepared for testing (Simms et al., 2007). The pumping gravimetric water content was calculated from the measured void ratio at slurry conditions assuming $100 \%$ saturation. As indicated previously, drying begins immediately after the material has been deposited, even before self-weight consolidation has taken place. The authors believe that in order to model void ratio evolution, the properties of the material should correspond to those associated to the slurry material. In this paper, an initial void ratio of 1.35 was assumed and considered, consistent with the measured data of settling and self-weight consolidation shown in Figure 2. The contribution of this paper lies in incorporating the dependence between saturated hydraulic conductivity and void ratio and also in the fact that the results have been shown, in terms of void ratio, by fitting the shrinkage curve with a theoretical relation.

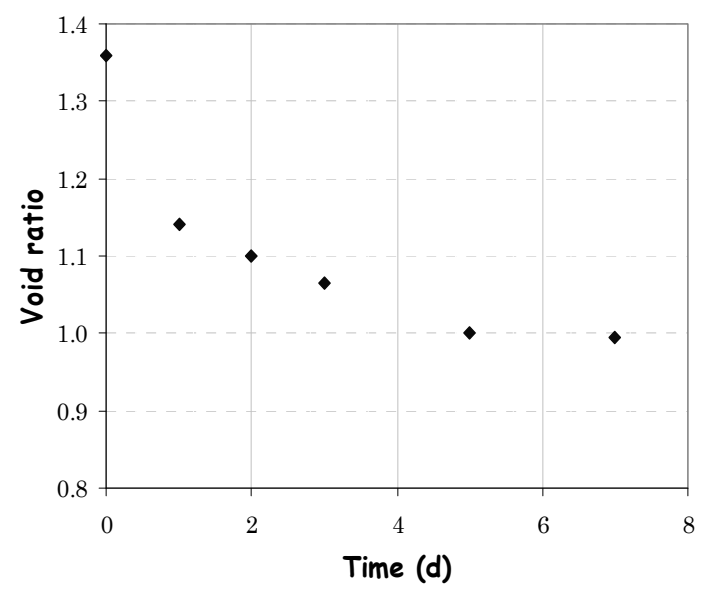

Figure 2 Typical void ratio versus time relationship from self-weight consolidation of Bulyanhulu paste tailings 


\subsection{Shrinkage}

Void ratio also changes as a result of drying and this behaviour is represented by the shrinkage curve. The shrinkage data for the Bulyanhulu tailings was obtained from previous research by Simms et al. (2007) and is shown in Figure 3. This set of data is referred to in this paper as 'original data'. It should be noted that the original data for the shrinkage curve starts at a void ratio of approximately 0.97 , as the laboratory tests were developed for the material after settling and self-weight consolidation had taken place.

A continuous representation of the shrinkage curve is needed for the analysis, thus a mathematical equation was fitted to the data obtained in the laboratory. This mathematical representation provides estimates of the void ratio at any given suction. The fitted shrinkage curve shown in Figure 3 was obtained using Equation (1) (Fredlund, 1999) with $\mathrm{a}_{s h}=0.79, \mathrm{~b}_{s h}=0.265$, and $\mathrm{c}_{s h}=12$. Figure 3 also shows the shrinkage curve both in terms of gravimetric water content (GWC) and suction based on the Equation (2) for the soil water characteristic curve subsequently presented in this paper.

$$
\left.e(w)=a_{s h} \cdot\left[\frac{w^{c_{s h}}}{b_{s h}^{c_{s h}}}+1\right]\right]^{\left(\frac{1}{c_{s h}}\right)}
$$

Where:

$$
\begin{array}{lll}
\mathrm{e}(\mathrm{w}) & = & \text { void ratio as a function of gravimetric water content. } \\
\mathrm{w} & = & \text { gravimetric water content. } \\
\mathrm{a}_{\mathrm{sh}} & = & \text { minimum void ratio. } \\
\mathrm{b}_{\mathrm{sh}} & = & \text { slope of the line of tangency. } \\
\mathrm{c}_{\mathrm{sh}} & = & \text { curvature of the shrinkage curve. }
\end{array}
$$
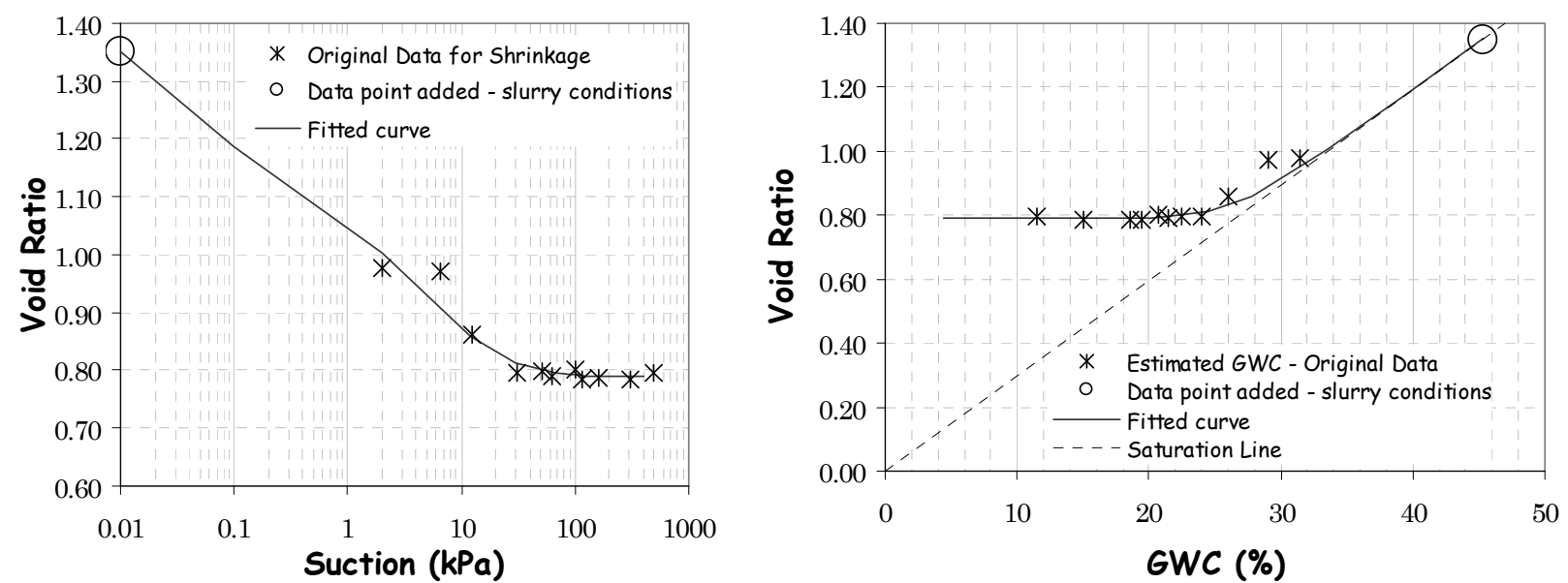

Figure 3 Shrinkage curve in terms of GWC and suction

\subsection{Soil water characteristic curve (SWCC)}

The SWCC is the property that relates suction to saturation, volumetric water content, or gravimetric water content. The SWCC of the Bulyanhulu tailings was also obtained from previous research by Simms et al. (2009a) and is presented in Figure 4. The fitted SWCC shown in Figure 4 was obtained from Equation (2) using $\mathrm{a}_{f}=996.32, \mathrm{~m}_{f}=4.155$, and $\mathrm{n}_{f}=0.367$. 


$$
w_{w}=w_{s}\left[1-\frac{\ln \left(1+\frac{\psi}{h_{r}}\right)}{\ln \left(1+\frac{10^{6}}{h_{r}}\right)}\right] \cdot\left[\frac{1}{\left(\ln \left(\exp (1)+\left(\frac{\psi}{a_{f}}\right)^{n_{f}}\right)\right)^{m_{f}}}\right]
$$

Where:

$$
\begin{array}{lll}
\mathrm{w}_{\mathrm{w}} & = & \text { water content. } \\
\mathrm{w}_{\mathrm{s}} & = & \text { saturated water content. } \\
\psi & = & \text { suction }(\mathrm{kPa}) . \\
\mathrm{h}_{\mathrm{r}} & = & \text { soil suction related to residual water content }(\mathrm{kPa}) . \\
\mathrm{a}_{\mathrm{f}} & = & \text { fitting parameter related to the air entry value of the soil. } \\
\mathrm{n}_{\mathrm{f}} & = & \text { fitting parameter related to the maximum slope of the curve. } \\
\mathrm{m}_{\mathrm{f}} & = & \text { fitting parameter related to the curvature of the slope. }
\end{array}
$$
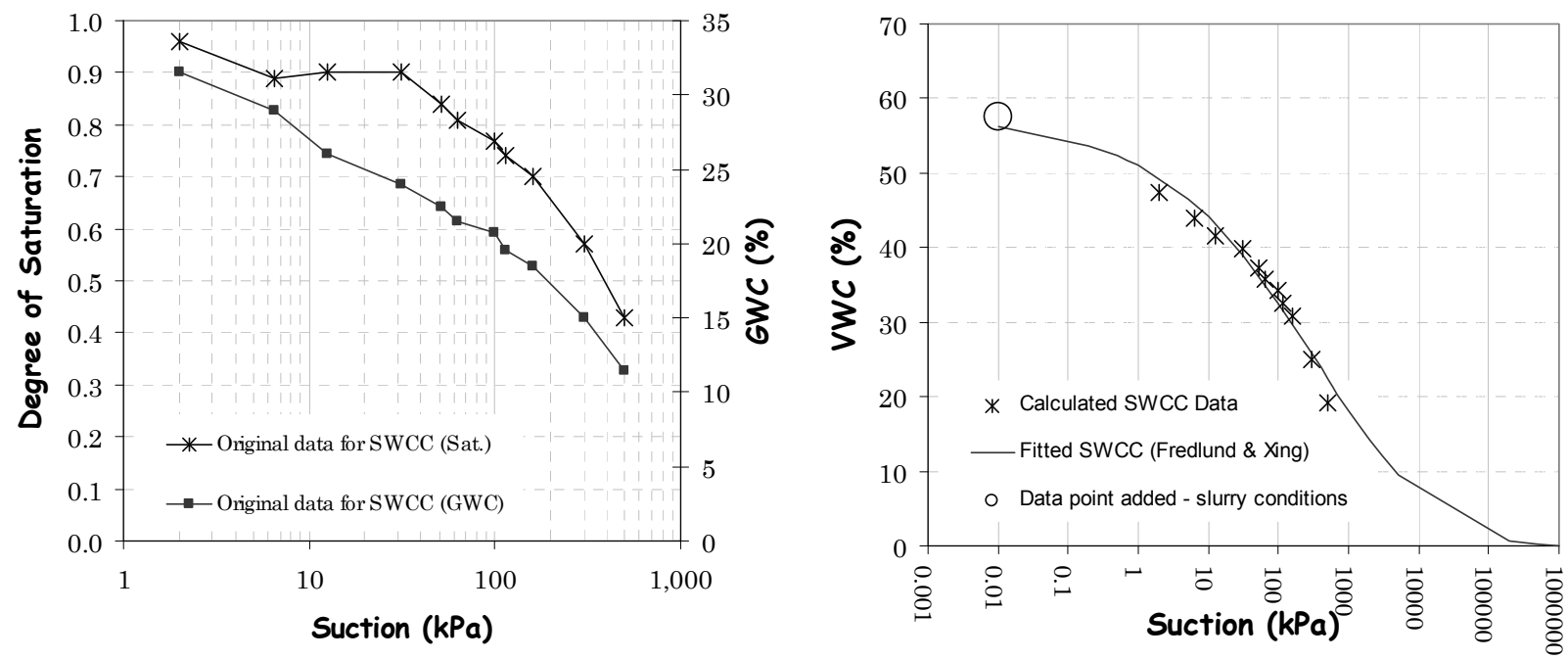

Figure 4 Soil water characteristic curve for Bulyanhulu paste tailings

\subsection{Permeability function}

One of the key parameters in unsaturated flow modelling is hydraulic conductivity. Although saturated hydraulic conductivities are easy to obtain, measuring the unsaturated hydraulic conductivity may be extremely difficult, time consuming and costly. Several models have been proposed to predict the unsaturated permeability function based on the SWCC data. Consistent with the model used to fit the SWCC, the Fredlund and Xing (1994) model has been selected here to estimate the unsaturated hydraulic conductivity function. Initially, a saturated hydraulic conductivity of $5 \times 10^{-7} \mathrm{~m} / \mathrm{s}$ was considered. Figure 5 shows the relation between hydraulic conductivity and suction obtained with this model. It can be observed that the calculated hydraulic conductivity function does not show a clear air entry value (AEV) and that hydraulic conductivities drop drastically even at very low suctions. As will be shown later in this paper, some modifications must be performed to obtain a more representative hydraulic conductivity function for the material. 


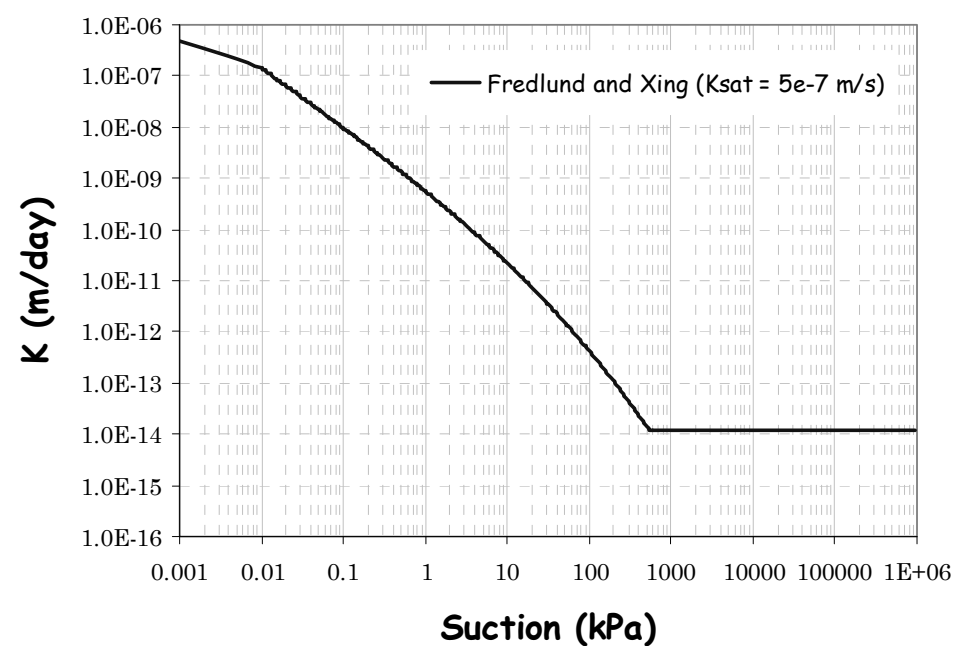

Figure 5 Estimated hydraulic conductivity function for Bulyanhulu paste tailings

\section{$4 \quad$ Modelling and results}

Modelling void ratio evolution due to drying can be achieved in a three-stage process. First, the suctions are determined through numerical modelling using any unsaturated flow software. The computed suction values are then related to water contents using the SWCC and the water contents can finally be converted to void ratio using the shrinkage curve. Depending on how the shrinkage curve was determined in the laboratory, suction values may be directly related to void ratio making this a simple two-stage process.

For the purpose of this paper, the drying and re-saturation stages of a given paste layer have been modelled using the saturated/unsaturated flow model SoilCover ${ }^{\circledR}$ (Wilson et al., 1994). SoilCover has been widely used to model the soil atmosphere interface for different applications. SoilCover uses a physically based method for predicting the exchange of water and energy between the atmosphere and the soil surface. The theory is based on the principles of Darcy's and Fick's Laws, which describe the flow of liquid water and water vapour, and Fourier's Law to describe conductive heat flow in the soil profile below the soil/atmosphere boundary. The rate of evaporation from the soil surface is calculated based on atmospheric conditions (radiation, wind speed, temperature, and relative humidity) and soil properties and conditions. The modified Penman formulation proposed by Wilson (1990) is used to compute the actual rate of evaporation at the soil-atmosphere boundary.

SoilCover is a flow model and changes in total stresses are not represented. Nevertheless, in arid climates it is expected that the rate at which void ratio decreases is primarily driven by the suction forces generated during drying and it has been assumed that the settling and self-weight consolidation effects are negligible.

\subsection{Drying tests}

Model results were compared to the data obtained from drying tests performed with Bulyanhulu tailings at Carleton University (Bryan, 2008). These results were used as a benchmark to determine the validity of the proposed model and to evaluate the reliability of the void ratio estimates. The lab scale-drying test consisted of two consequent layers of tailings that were deposited at the pumping gravimetric water content. The first layer was allowed to dry for 15 days before the second layer was placed on top. The second layer dried for only 11 days under conditions less conducive to evaporation. During this process, relevant parameters such as wind speed, temperature, relative humidity, pan A evaporation and suction values were measured so that they could be input into the numerical models. Also, the actual evaporation rate and void ratio for each paste layer were determined by measuring the weight and volume changes of the paste.

The drying test data provided by Bryan (2008) are used in the present study as the benchmark to determine the accuracy of the results obtained under the modelling framework. In order to do so, the results are compared in terms of actual and total evaporation as well as void ratio. 


\subsection{Model results versus drying tests results}

An initial model was developed using the input parameters described in the previous sections. The results are compared to the measured evaporation rates in the drying tests performed by Bryan (2008) to assess the validity of the model and are shown in Figure 6.

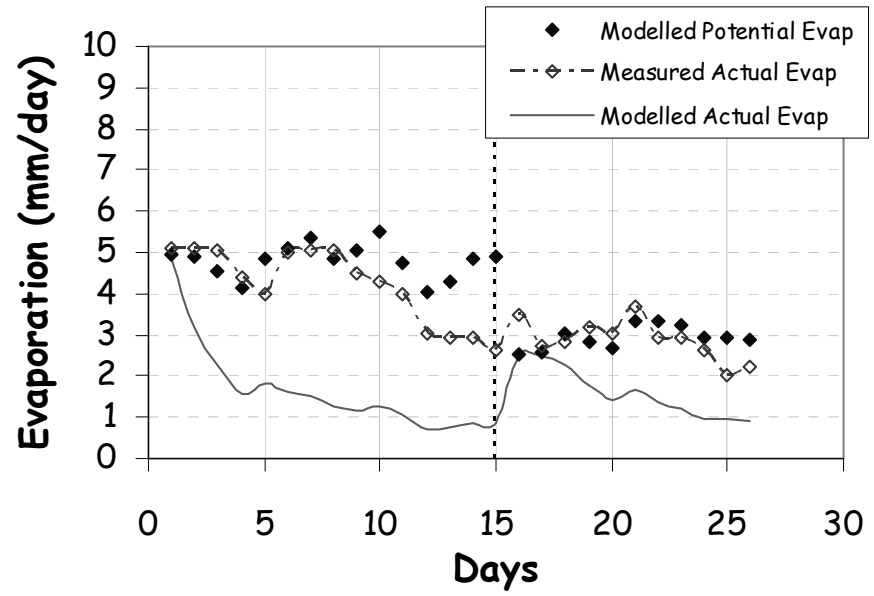

Figure 6 Measured and modelled evaporations

As can be seen in Figure 6, the modelled data did not correlate well with the measured evaporation. This is attributed to the fact that high suctions developed in the upper layers of the model, which in turn decreased the hydraulic conductivity to a point where evaporation is almost suppressed. The problem was solved in previous research by Simms et al. $(2007,2009$ a) by using the true degree of saturation versus suction curve to estimate the hydraulic conductivity function. The saturation curve was obtained from measured volume change during the SWCC test. The relative hydraulic conductivity function obtained by this fit has a lesser gradient in the low suction range, which causes the hydraulic conductivity to decrease less than if a hydraulic conductivity function was obtained from a SWCC without considering the true degree of saturation.

The approach used in this paper is the first attempt to consider the variability in hydraulic conductivity with both void ratio and drainage. This was accomplished by coupling the $\mathrm{K}_{\text {sat }}$ values measured during settling tests with the values of K determined from fitting the SWCC data. The measured values of $\mathrm{K}_{\text {sat }}$ were used to determine the shape of the $\mathrm{K}$ function in the low suction range before the air entry value (AEV) is reached (material is still saturated). For higher suctions (above the AEV), K values were obtained from the Fredlund and Xing (1994) model using the SWCC data. It must be noted that the hydraulic conductivity function was determined based on preliminary results obtained from settling tests and it is only the first attempt to obtain a function for $\mathrm{K}$ that accounts for changes in void ratio.

Additionally, the saturated hydraulic conductivity for the slurry conditions is believed to be higher than that obtained for the settled conditions and therefore this aspect has been also considered when defining the $\mathrm{K}$ function used in the models presented herein. Initial measurements developed during settling tests have indicated that the saturated hydraulic conductivity for the slurry material is at least one order of magnitude higher than that measured for the settled material (corresponding to $5 \times 10^{-7} \mathrm{~m} / \mathrm{s}$ ). According to these preliminary findings, a saturated hydraulic conductivity of $5 \times 10^{-6} \mathrm{~m} / \mathrm{s}$ was used for the models presented herein.

As shown in Figure 7, an improved correlation with the measured data is obtained if the proposed changes are made to the hydraulic conductivity function. 


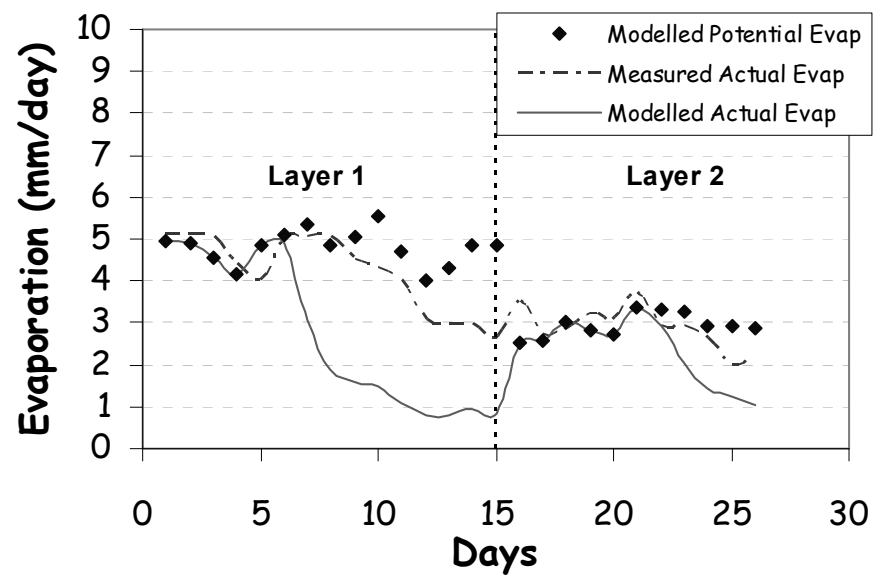

Figure 7 Measured and modelled evaporations using the modified hydraulic conductivity function

The average void ratios measured during the drying tests performed by Bryan (2008) were also compared to those obtained by the present model. The results for the computed void ratio for the first layer are shown in Figure 8. Although some discrepancy is found at day 3, the modelled void ratios are still on the conservative side.

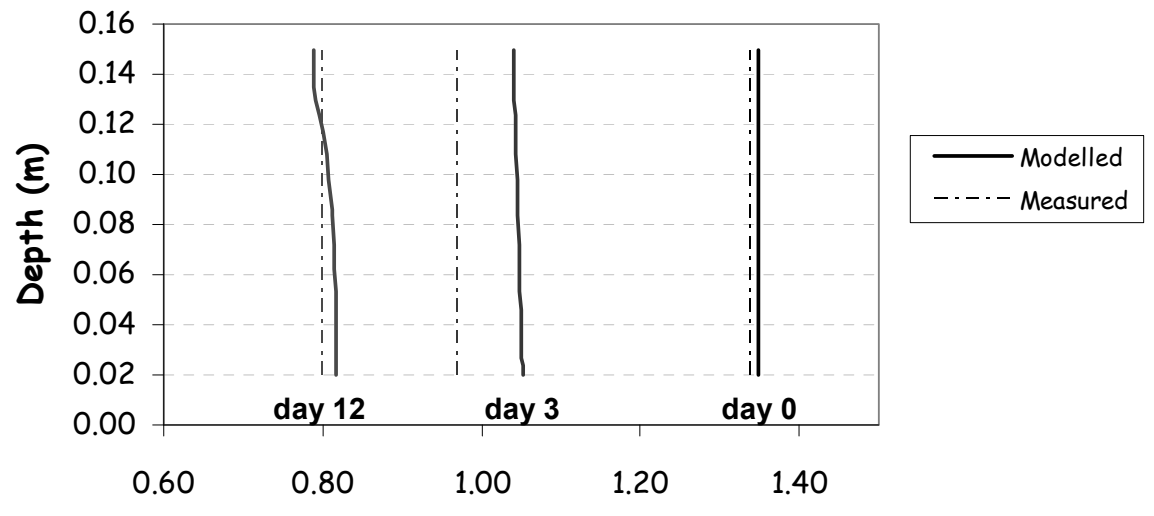

Void Ratio

Figure 8 Measured and modelled void ratios

\section{Applications of the modelling framework to paste tailings management and design}

As shown above, void ratio evolution of a paste tailings layer can be predicted with a reasonable degree of confidence using saturated/unsaturated soil-atmosphere modelling. During design stages, this framework gives the flexibility of being able to predict the post depositional characteristics of the paste under different climatic, operational and site conditions. The results obtained using this approach could help evaluating the optimal depositional scheme and can be used as a decision making tool during design. Some of the questions that may be addressed with this approach are the following:

- How much time is required to achieve a target density, void ratio or strength under a given climate?

- What is the optimum layer thickness that should be used to achieve a specific density, void ratio or strength?

- What is the maximum theoretical slope that can be constructed under given climatic conditions without compromising the factor of safety for liquefaction? 
- How could weather conditions affect the post depositional behaviour of the paste (differences between winter and summer conditions for example)?

- What is the contribution to shrinkage in a freshly deposited paste layer due to downward seepage to underlying previously dried layers of paste?

- What is the most suitable curve to use for the evaluation of consolidation?

The answer to these questions may be obtained by modelling different case scenarios in which the relevant input parameters are modified to determine their effect over the void ratio estimates. The effect of layer thickness, climatic conditions, drying time, and other parameters can be evaluated and used for determining the appropriate depositional scheme, as will be shown in the following sections.

\subsection{The effect of paste layer thickness}

The effect of layer thickness was evaluated by executing three different models with thicknesses of 15,30 and $60 \mathrm{~cm}$.

As shown in Figure 9, thinner layers will accelerate drying, allowing the paste layer to reach the shrinkage limit faster than thicker layers. As observed, the $15 \mathrm{~cm}$ thick layer has reached the shrinkage limit by day 10, while the $30 \mathrm{~cm}$ layer requires 15 days to reach this same stage but only at the top of the layer. On the other hand, the $60 \mathrm{~cm}$ layer does not reach the shrinkage limit even after 15 days of drying. It is also observed that for thicker layers, shrinkage first occurs closer to the surface as water from the lower portion is not being released. In some cases, this could lead to the formation of a surface crust that may suppress water removal from the lower sections of the layer, thus reducing the potential of gaining strength due to drying. For thinner layers, water seems to be removed from the full profile, making the void ratio to be almost uniform within the layer.
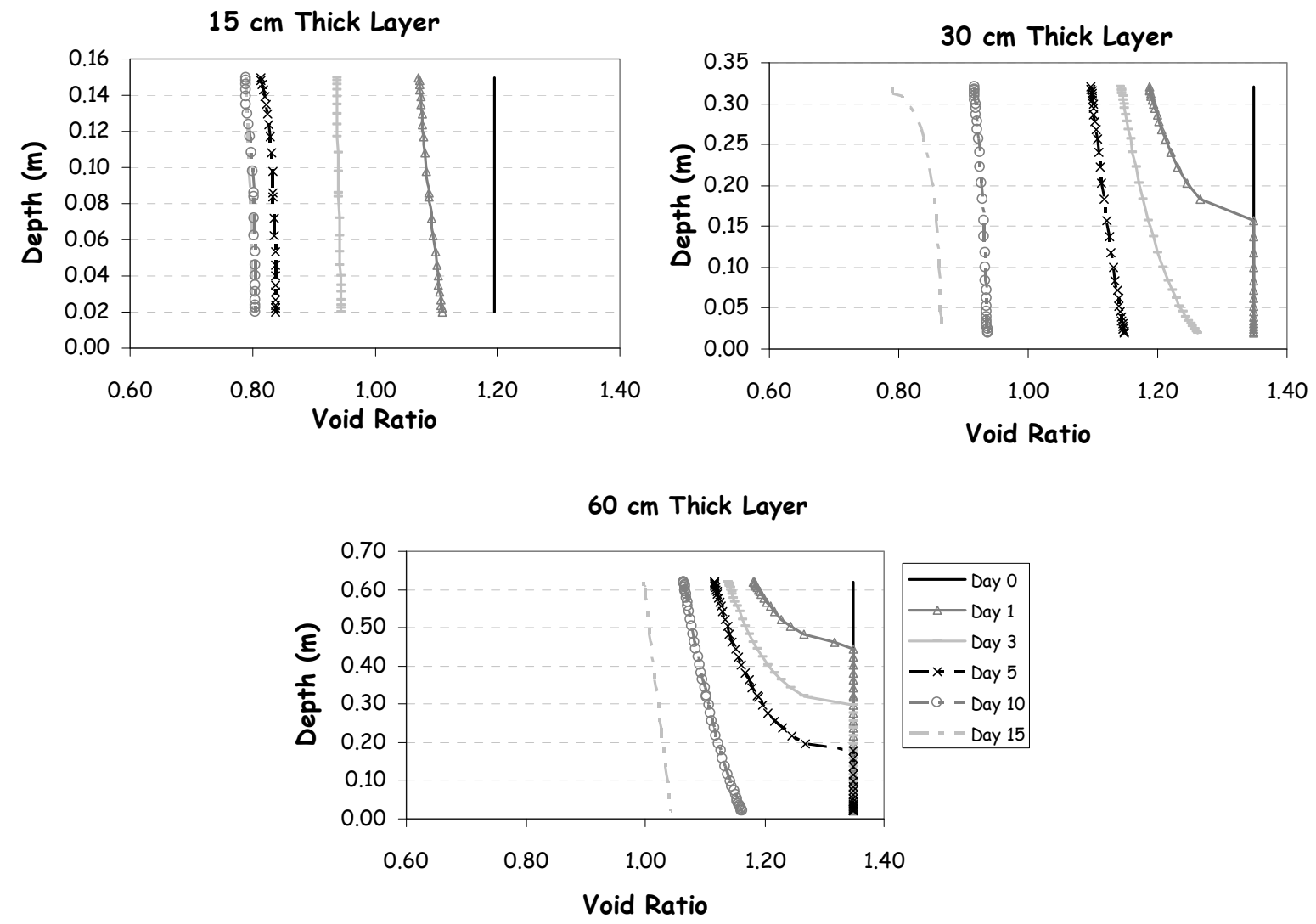

Figure 9 The effect of layer thickness on the distribution of void ratio 


\subsection{The effect of climate}

Another application of the model described herein is to determine the effects of different climatic conditions on the post depositional behaviour of the paste. For example, this may be of help to evaluate if different operational procedures are required between summer and winter conditions. The effect of climate was assessed by comparing two cases with potential evaporations of $1.8 \mathrm{~mm} / \mathrm{d}$ and $4.5 \mathrm{~mm} / \mathrm{d}$ for a $15 \mathrm{~cm}$ thick paste layer. The high potential evaporation model is assumed to be representative of summer conditions or dry seasons while the low evaporation case is representative of winter conditions or humid weather. As shown in Figure 10, under high evaporation conditions, the paste layer has almost reached the shrinkage limit of 0.79 by day 10 , while for the same material but under less evaporative conditions the void ratio at day 10 is close to 1.0. In this last case, even after 15 days of drying the material seems to have not been able to reach the shrinkage limit. As achieving the maximum possible density is one of the primary goals during operation, then different drying times may be required in winter and summer.
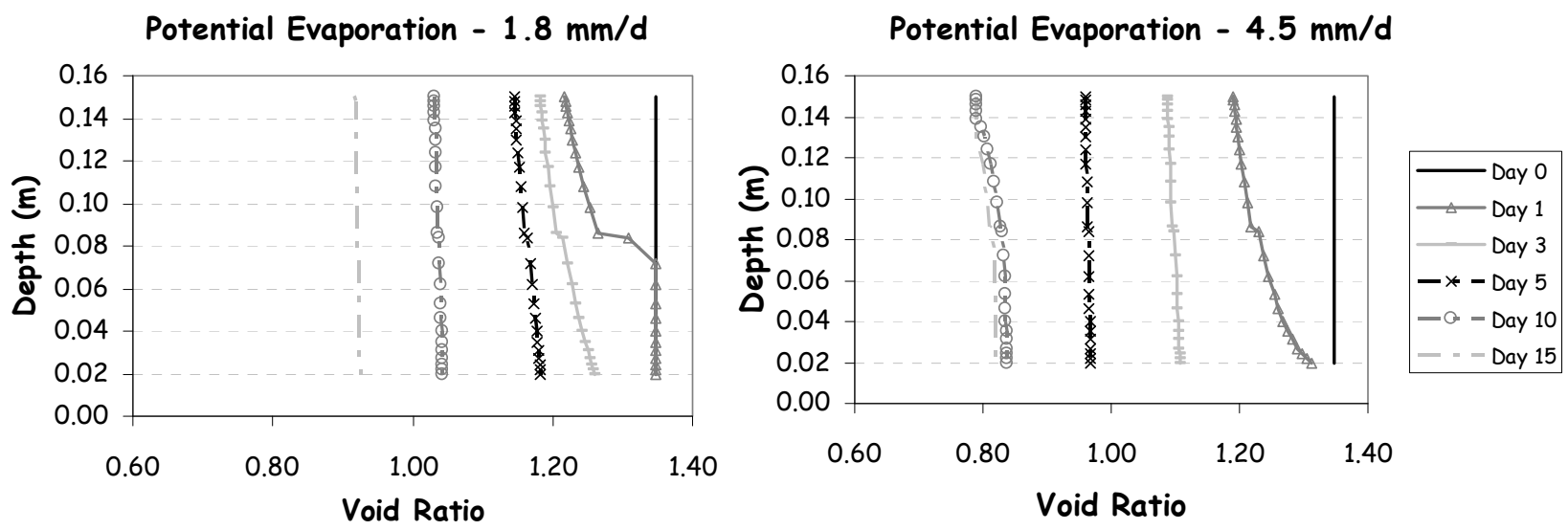

Figure 10 The effect of climate on the distribution of void ratio $(15 \mathrm{~cm}$ layer)

\subsection{The effect of drying time}

In general terms, the influence of drying time may seem quite obvious, i.e. increasing density with increasing drying time. Nevertheless, predicting the time required to achieve a target density cannot be achieved without the use of a model. For example, if density was to be maximised, then interest would be to determine the amount of time required to achieve the maximum density due to drying, which in turn, is obtained at the shrinkage limit. Then, the problem is reduced to determining the time required to reach the void ratio at the shrinkage limit under given climatic conditions. It must be noted that once the shrinkage limit has been reached, no further volume change will occur due to desiccation; therefore, drying the paste beyond this point is not required. The evolution of void ratio with time for a $15 \mathrm{~cm}$ thick paste layer under two different climatic conditions is shown in Figure 11.

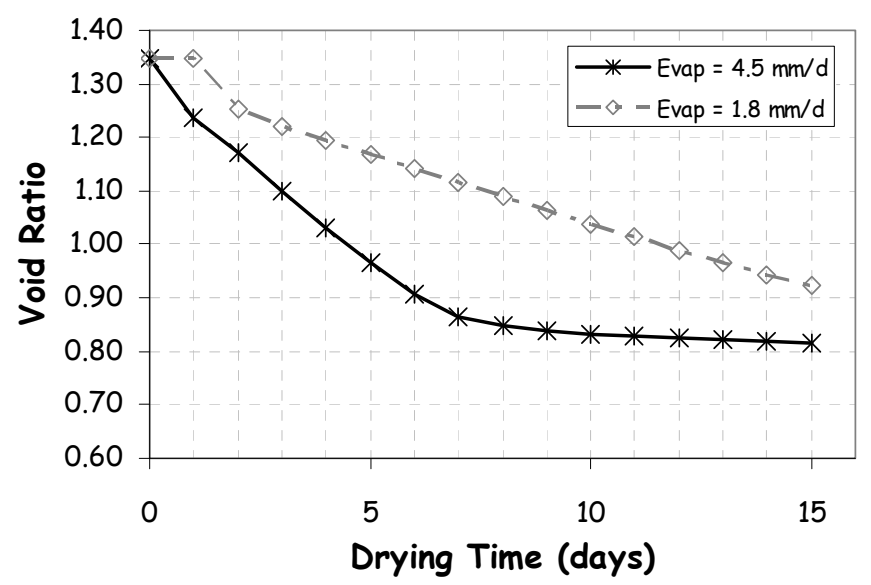

Figure 11 Average void ratio as a function of drying time 


\subsection{The effect of drainage to previously dried paste layers}

When a fresh paste layer is placed on top of previously dried layer, drainage will occur as a result of the high head gradients at the interface between the layers. Water from the fresh paste layer will be drawn out by negative pore water pressures in the dried layer enhancing the drying process and increasing the rate at which strength and density change.

While modelling the effect of drainage into previously dried paste layers, it is important to address the fact that the material properties of the dried paste are no longer the same as those initially considered. The dried layer has undergone shrinkage, and therefore, the saturated moisture content will no longer be the one measured under slurry conditions. Consequently, the SWCC for the dried material will be different from that initially used, and the saturated hydraulic conductivity is expected to be lower as a result of increased density due to drying.

The SWCC for the dried paste may be obtained in a simplified manner by calculating a new saturated water content based on the void ratio reached after drying as presented by Fisseha et al. (2010). The resulting SWCC of the dry material is shown in Figure 12, along with the SWCC used for the slurry. Both curves have been fitted using Equation (2) (Fredlund and Xing, 1994).

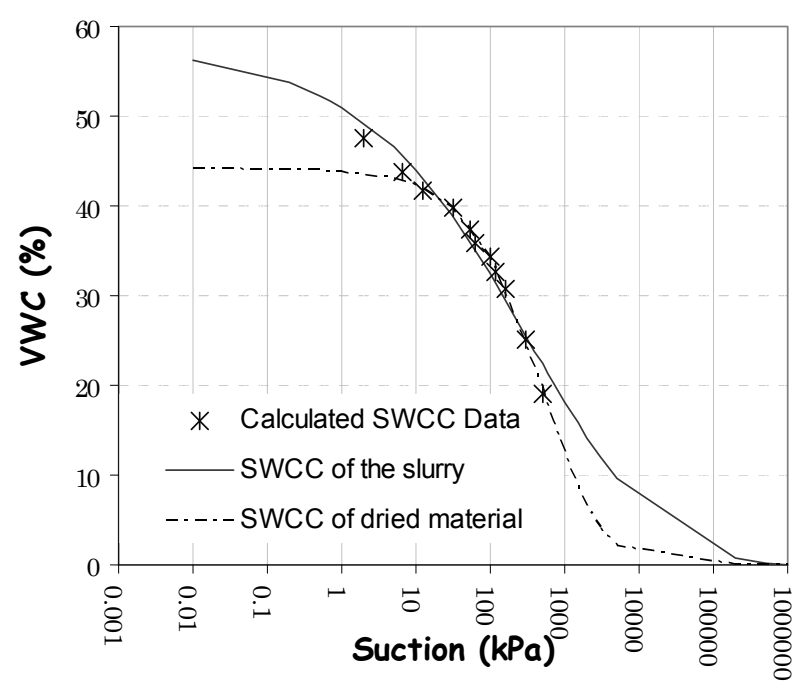

Figure 12 Modified SWCC for the dry paste

The saturated hydraulic conductivity for the dried paste layer can be obtained from consolidation test results where hydraulic conductivity and void ratio can be related.

Figure 13 presents the results of having a fresh layer of paste deposited on a previously dried layer under the same climatic conditions. As observed, a portion of the water in the fresh layer flows to the underlying dried paste layer enhancing the drying process and making possible for the shrinkage limit to be reached in less amount of time compared to that obtained for the first layer. Similar observations have been noted by Fisseha et al. (2010). 


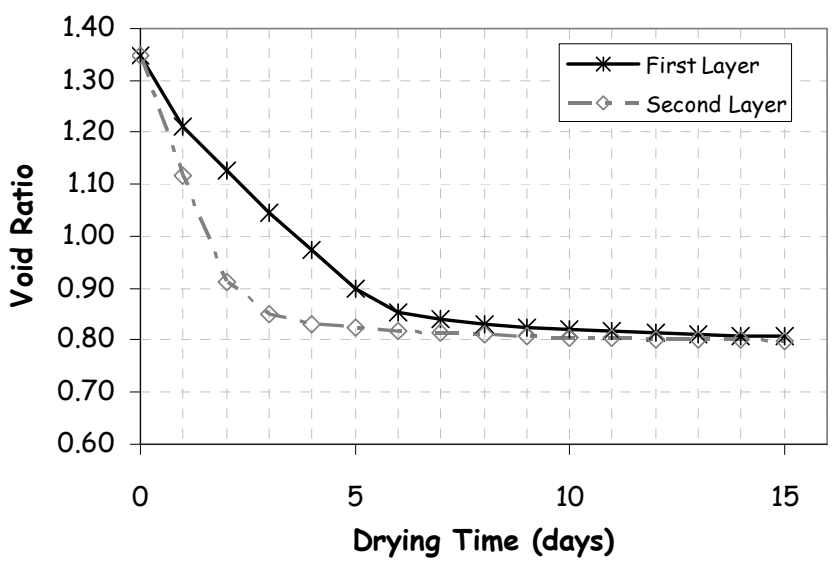

Figure 13 The effect of drainage to previously dried paste layers

Simms et al. (2010) also examined the influence of a deep, previously desiccated stack on the drying of a fresh layer. It was found through numerical modelling that for a sufficiently high hydraulic conductivity (at least $1 \times 10^{-8} \mathrm{~m} / \mathrm{s}$ ) the underlying stack may retard the desiccation of the fresh layer, as water from the whole stack supplies the evaporation demand at the surface. It was also found that the degree of saturation of the stack has a big impact on the distribution of moisture. Underlying stacks with high degrees of saturation tend to decrease the drying rate of a freshly deposited layer, while very dry stacks could enhance it.

Another important aspect of desiccation, which is not considered herein, is the effect of salt accumulation at the surface. Dunmola and Simms (2010) have shown that out of the three main contributors to evaporation suppression, i.e. osmotic effect, albedo, and physical crust formation, the effect of suppression of vapour pressure due to the osmotic action can explain most of the reduction in evaporation due to salts. Fisseha et al. (2010) performed analyses to predict the rate of salt accumulation on the surface. The drawdown in evaporation attributed to salt accumulation was then coupled to the model.

\section{Discussion}

The authors acknowledge that further improvements could be made to the hydraulic conductivity function used in the models. Research is underway to determine the differences in saturated hydraulic conductivity of the slurry and the material after self-weight consolidation. The changes in $\mathrm{K}$ between these two states are considered important for the early stages of drying. Although the models presented herein have considered preliminary measurements for hydraulic conductivities at the slurry conditions, a consistent methodology should be developed to couple the whole range of measured and predicted hydraulic conductivities (from slurry to dry conditions).

Further iterations of the approach presented in this paper are planned to determine the most suitable way of accounting for changes in hydraulic conductivity as a consequence of volume change and drying. One of the goals will be to determine whether the variability of $\mathrm{K}$ due to volume changes should be included in the hydraulic conductivity function curve used in the unsaturated modelling or by just changing the value of $\mathrm{K}_{\text {sat }}$ at every time step during modelling.

Including the effect of settling and self-weight consolidation into the modelling approach presented herein is also one of the goals of this research.

\section{$7 \quad$ Summary and conclusions}

Void ratio evolution of a paste tailings layer can be undertaken using saturated/unsaturated flow modelling. In order to achieve this goal, care should be taken when determining the material properties for the model. The authors believe that for obtaining meaningful results for void ratio, the properties of the paste used for the modelling should be representative of the slurry conditions. If slurry conditions are used, the full range of void ratios can be predicted through the numerical modelling of drying (void ratios may be modelled starting 
at the slurry or out of pipe conditions up to the shrinkage limit). Special care should be undertaken when determining the hydraulic conductivity function for the model, as results are extremely sensitive to this parameter. The authors believe that an appropriate $\mathrm{K}$ function should consider measured values of $\mathrm{K}$ until the $\mathrm{AEV}$ is reached. After this point, $\mathrm{K}$ can be obtained by fitting some of the existing unsaturated models to the SWCC data.

The findings of this study suggest thin layer deposition is a key requirement for increasing density due to drying. Thicker layers may require twice the time, or even more, to reach the same density or void ratio. The optimum thickness and drying times are case-specific but may be determined under a modelling approach similar to the one presented in this paper. Results indicate that drying times may be limited to that required to reach the shrinkage limit of the material, as no further density will be gained due to drying after this point. Drainage into a previously dried layer may significantly contribute to increasing the rate at which void ratio decreases; therefore, it is important to attribute the right properties of previously dried layers to obtaining representative results from modelling.

Outcomes of void ratio from modelling, such as those described, herein, can be used during design stages as a tool for determining optimal depositional schemes. These results may also give a first estimate of the void ratio that can be achieved under a given climate before the next paste tailings lift is placed. The increased reliability on the initial void ratio or density from the proposed modelling framework may help increasing the confidence in liquefaction assessments. There is potential for the approaches to be extended to the oil sands industry, where the increase of undrained shear strength due to drying may be effectively modelled under this approach.

\section{Acknowledgements}

The authors would like to acknowledge Golder Associates Ltd. and the Natural Sciences and Engineering Research Council of Canada (NSERC) for funding the research presented in this paper.

\section{References}

Bryan, R. (2008) Drying and Oxidation of Surface Disposed Paste Tailings, Master of Applied Science Thesis, Carleton University, Ottawa, Ontario, Canada.

Dunmola, A. and Simms, P. (2010) Solute mass transport and atmospheric drying of high-density gold tailings, in Proceedings Thirteenth International Seminar on Paste and Thickened Tailings (Paste2010), R.J. Jewell and A.B. Fourie (eds), 3-6 May 2010, Toronto, Canada, Australian Centre for Geomechanics, Perth, pp. 279-289.

Fisseha, B., Bryan, R. and Simms, P. (2010). Evaporation, unsaturated flow and salt accumulation in multilayer deposits of a 'paste' tailings, ASCE Journal of Geotechnical and Geoenvironmental Engineering, In Press.

Fredlund, D. and Xing, A. (1994) Equations for the Soil Water Characteristic Curve, Canadian Geotechnical Journal, Vol. 31, pp. 521-532.

Fredlund, M.D. (1999) The Role of Unsaturated Soil Properties Functions in the Practice of Unsaturated Soil Mechanics, PhD Thesis, University of Saskatchewan, Saskatoon, Canada.

Simms, P. Dunmola, A. and Fisseha, B. (2009b) Generic predictions of drying time in surface deposited thickened tailings in a 'wet' climate, in Proceedings of Tailings and Mine Waste 2009, University of Alberta, Banff, Alberta, November 1-4 2009, pp. 749-758.

Simms, P., Dunmola, A., Fisseha, B. and Bryan, R. (2010) Generic modelling of desiccation for cyclic deposition of thickened tailings to maximize density and to minimize oxidation, in Proceedings Thirteenth International Seminar on Paste and Thickened Tailings (Paste2010), R. Jewell and A.B. Fourie (eds), 3-6 May 2010, Toronto, Canada, Australian Centre for Geomechanics, Perth, pp. 293-301.

Simms, P., Fisseha, B. and Bryan, R. (2009a) Evaporation, Unsaturated Flow, and Salt Accumulation in Multilayer Deposits of a Paste Gold Tailings, in Proceedings Twelfth International Seminar on Paste and Thickened Tailings (Paste09), R. Jewell, A.B. Fourie, S. Barrera, J. Wiertz (eds), 21-24 April 2009, Viña Del Mar, Chile, Gecamin Limited, Santiago, pp. 251-260.

Simms, P., Grabinsky, M.W. and Zhan, G. (2007) Modelling Evaporation of Paste Tailings from the Bulyanhulu Mine, Canadian Geotechnical Journal, Vol. 44, pp. 1417-1432.

Wilson, G.W. (1990) Soil Evaporative Fluxes for Geotechnical Engineering Problems, Ph.D Thesis, University of Saskatchewan, Saskatoon, Canada.

Wilson, G.W., Fredlund, D.G. and Barbour, S.L. (1994) Coupled Soil-Atmosphere Modelling for Soil Evaporation, Canadian Geotechnical Journal, Vol. 31(2), pp. 151-161. 
